\title{
Middle School Students' Free-living Physical Activity on Physical Education Days, Non-physical Education Days, and Weekends
}

\author{
Risto Marttinen ${ }^{1}$, Ray N. Fredrick III', Stephen S. Silverman ${ }^{2}$
}

Affiliations: 'California State University, Fullerton, College of Health \& Human Development, Department of Kinesiology, Fullerton, CA, USA, ${ }^{2}$ Columbia University, Teachers College, New York, NY, USA

Correspondence: R. Marttinen, California State University, Fullerton, College of Health \& Human Development, Department of Kinesiology, Fullerton, 800 N. State College Blvd, Fullerton, CA, 92831, USA. E-mail: rmarttinen@fullerton.edu

ABSTRACT This study measured students' free-living Physical Activity (PA) in order to examine activity patterns of youth. Students $(N=221)$ in 12-classes wore accelerometers to measure their PA over six weeks in and out-of-school while participating in a fitness unit. PA was significantly higher during Non-PE-Days and PE-Days than on Sundays. PA was significantly higher during baseline than weeks five and six. There were no significant differences between boys and girls in the number steps taken. Eighth-grade students had the lowest PA levels. On average, the students were attaining 60 minutes of MVPA. Students, however, did not often reach national recommendations. Girls reached their national recommendations five out of six weeks on days that they participated in PE. The results suggest that specific subgroups, such as adolescent girls, are getting the recommended PA but only when the PA is structured. A spike in PA during the first week suggested a possible motivational effect of the accelerometer.

KEY WORDS physical education, adolescent, accelerometer

@MJSSMontenegro

PA LEVELS OF MIDDLE SCHOOL YOUTH

http://mjssm.me/?sekcija=article\&artid=146

Physical activity levels have often been targeted in curriculum interventions that attempt to reverse the trend of obesity and overweight students (Dudley, Okely, Pearson, \& Cotton, 2011). There is no doubt that the obesity epidemic is a hot topic in the media and in much of the health and physical education literature around the world (Eaton et al., 2012, U.S. Department of Health and Human Services (DHHS), 2008). Students and teachers alike are being bombarded with facts about rising obesity and overweight numbers and the ill health effects that come as a result of an inactive lifestyle.

Health issues have been the mainstay of discussion for many years in the field of physical education research. In the U.S.A., national initiatives like the Healthy People 2020 goals (DHHS, 2008) and the NASPE standards (NASPE, 2012), to name two, attempt to disseminate information about the harmful effects of a sedentary lifestyle and the benefits of becoming and staying physically active. These initiatives often compete with a well-documented trend that is increasingly more common in schools calling for a reduction in physical education classes and recess to spend more time in the classroom learning academic subjects in the face of high stakes testing (IOM, 2013). This plan is short-sighted as research suggests that increasing physical education and physical activity time in school does not negatively affect academic scores in other subjects (IOM, 2013). Some research even indicates increases in student academic performance with time spent in physical education (Sallis et al., 1999).

Despite the results research conducted in the field of physical education and the known benefits of physical activity, the majority of youth do not reach the recommended standard of physical activity (PA) (IOM, 2013). The declining trend in youth PA levels is troubling, as physical activity has been shown to reduce the risk of developing chronic diseases (CDC, 1997). The recommended amount of physical activity for young people aged 6 to 17 is 60 minutes a day (DHHS, 2008). In 2009, according to a national survey, less than 20\% of students met these guidelines of adequate physical activity (Eaton et al., 2012). 
Youth PA levels have been monitored in various ways, ranging from PA interventions with researcher observation such as SOFIT (McKenzie, Sallis \& Nader, 1991), self-report instruments, such as 3DPAR (Pate et al., 2003), as well as activity monitors, such as accelerometers (Stewart, Dennison, Kohl \& Doyle, 2004) and pedometers (Ho et al., 2013). The free-living PA of middle school students has not often been measured, especially for an extended time. Often the reasoning for short bursts of measurement is the risk of losing expensive equipment that measures PA. Additionally, it often is difficult to measure PA objectively when a researcher is not present, such as when students are not in school.

Integrating technology into educational situations has been recommended as an effective tool to supplement learning (NASPE, 2009). Research suggests that including technology in instruction can lead to a positive influence on both students and teachers (Gibbone, Rukavina \& Silverman, 2010). To date, however, few studies have examined the implementation of technology into the PE curriculum as an educational tool to monitor PA levels or motivate students to increase PA. Examining students' PA levels with accelerometers that are also used as an educational tool could shed more light on the PA levels of youth in free-living environments.

Previous research has demonstrated significantly higher MVPA on days that students have physical education class than when they do not (Chen, Kim \& Gao, 2014). Many studies, however, only tracked students for a relatively short period (7-14 days). Therefore, the purpose of this study was to measure students' physical activity levels in a free-living environment over the course of six weeks, which is roughly equivalent to a typical unit of instruction in physical education.

\section{Methods}

These data were collected as a part of a larger study that measured multiple variables of students and teachers who participated in the research project.

\section{Participants}

A total of 221 students participated and produced data for the study and were included in the final data analysis. Initially, 258 students began the study, but 37 were dropped due to insufficient readings for PA, questionable and/or invalid scores, or the inability to sufficiently understand and read English to answer the questions posed to them in the greater study. The mean age of participants was $11.96( \pm 0.943 \mathrm{SD})$. Students ranged from $6^{\text {th }}(N=74), 7^{\text {th }}(N=63)$, to $8^{\text {th }}(N=84)$ grade. A total of 115 male and 106 female students participated. There were 136 white and 85 non-white students in the study ( 31 Latino, 3 black, 42 Asian, 1 Pacific Islander, 8 mixedrace). The study consisted of 12 classes. The University Institutional Review Board approved this study. In addition, consent was obtained from all participants' parents. All students signed assent forms.

This study measured student PA levels over six weeks while teachers implemented a unit of instruction in 12 different physical education classes, in Grades 6, 7, and 8 in a major metropolitan area in the north-eastern U.S.A. Students wore wrist-worn accelerometers in and out of school over the course of the unit. Data were collected during the 2014-2015 academic year.

The schools in this study were public schools and consisted of two K-6 elementary schools, one Grade $6^{\text {th }}$ only school, and three Grade 7-12 schools with a combined middle and high school campus. All schools had the use of a gymnasium, outside space, and sufficient materials to teach lessons that the teacher chose to teach. Schools were in different socioeconomic areas. Teachers were split evenly by sex, with six male teachers and six female teachers. All teachers were certified physical educators with a range of teaching experience from a first-year teacher to one with 35 years teaching experience; this resembles a typical school district spread of experience.

\section{Instrumentation}

Physical activity levels were measured using the MOVband accelerometer. In a validity study, the MOVband was compared to a pedometer (NL-2000) that had been recommended for use in research (Crouter et al., 2003). The steps measured by the NL-2000 were significantly and positively correlated with the steps recorded by the MOVband (Menickelli et al., 2013). The Institute of Medicine has suggested that accelerometers are the best method for collecting information about energy expenditure for the low and middle ranges (IOM, 2013).

Instructional unit. All students participated in normal physical education classes that, at the time, were implementing a new PA unit, Fitness Integrated with Technology (F.I.T.) unit. The unit consists of a 12-lesson fitness-based unit broken into three themes. The basis of the unit was to deliver fitness-based knowledge while integrating academic subjects into a unit of instruction and empowering students to make their own plans for fitness. In addition, information and data from the accelerometers were used in the lessons.

Throughout the unit, teachers implemented their own general topics of teaching and supplemented that unit with the F.I.T unit. The F.I.T. unit acted as an umbrella over the teachers regularly selected unit plan, not in place of one. The teachers were not forced to augment their unit plans to teach the F.I.T. Unit. They were provided support to supplement their original lessons with fitness knowledge and the integration of technology. The main aspects of the F.I.T. unit were delivered in the introduction and closure of the lessons, when fitness terms were introduced and class discussions were held. The middle part of each lesson followed the plans set forth by the teacher according to his or her unit planning. More information about the F.I.T. unit can be found in Marttinen and Fredrick (2016). 


\section{Procedure}

Students were given accelerometers to wear around the clock (in- and out-of-school). Physical activity data were collected for each week and always included, at a minimum, a physical education day, a non-physical education day, a Saturday, and a Sunday. Student PA levels were recorded continuously for six weeks.

School entry and recruiting. Prior to the main study, the lead author made contacts in middle schools (teachers, principals, administrators). Access to the schools was gained through contacts that were made through the first author's time in teaching, cooperating professors, and through recommendations from the supervising researcher. The lead author visited all schools that showed an interest in the study as well as those that sent all teachers a two-page summary of the study that was passed on to the administration. The teachers were chosen because they appeared to have good rapport with students and were very willing to help the project along.

Orientation for teachers. Prior to the beginning of the study and official entry into the schools, the teachers were given an accelerometer to wear for one week. This was done so the teachers had a chance to become comfortable wearing the unit around the clock and to come to know its functions. Teachers were also given an opportunity to create a profile on the MOVband company's internet server before students received the accelerometers for the pre-test. During this orientation process, teachers were taught how to trouble shoot, how to help students view their profiles, and how to upload student data. After three days of wearing the accelerometers, the author checked with the teachers to see how they were using them, and whether they had questions on the how to use them or view their data. Seven days after issuing the accelerometer to the teachers, the start of the Week 1 phase began for the students. Teachers played a crucial role in the fidelity of the students, which means they needed to constantly remind students to keep accelerometers on their wrists and were suggested to wear the accelerometers themselves during the unit.

Students were asked to move about normally but to wear the accelerometer wherever they went. There was a heavy emphasis on "everywhere" (except when showering and swimming). It was imperative that students wear the accelerometer in their daily activities and not forget the unit at home.

The orientation sessions to wearing the MOVbands were completed in a computer lab or with a laptop computer in the gym when a computer lab was inaccessible. Teachers followed a written script to disseminate directions to the participants. As suggested by Trost et al. (2005), to ensure higher compliance in recording physical activity data, a frequently asked questions sheet was passed out to students in case they ran into problems or had questions on how to use the accelerometer. The researcher's email address was given to students for troubleshooting at any time. Students were asked to upload data as frequently as possible. The researcher manually uploaded data at least three times during the unit if students had their accelerometer on. At the conclusion of the unit, the senior researcher completed a final upload of accelerometer data, and students turned in their accelerometers.

\section{Data Analysis}

MOVband accelerometer data were requested from the MOVable company database and were delivered in Excel files broken down by hour and day in numbers of steps. The MOVband accelerometer data were uploaded into SPSS. Complete data for physical activity was considered if there were 10 hours or more of physical activity in the 24-hour period registered on the accelerometer.

Activity levels were calculated using the accelerometer data. A detailed literature search was completed regarding cut points and how many hours of data were needed for complete days, as well as the number of days to include in the analyses. To achieve reliability of 0.80 or better, Trost et al., (2005) suggest that four to five days of monitoring is necessary to calculate physical activity levels, other studies also suggest four days of monitoring (Tudor-Locke et al., 2009). Complete days were considered only if there were 10 or more hours of recorded data per day (Chinapaw et al., 2014). Studies showed a high reliability $(r=0.86)$, and sample size could be achieved when children with $<$ two days lasting $<10$ hours/day were included in analyses (Rich et al., 2013). Finally, both Saturday and Sunday were used; prior studies show that both need to be recorded to obtain an accurate measure of habitual physical activity (Scheers, Philippaerts \& Lefevre, 2012). For the purposes of data analysis, scores were calculated from four days of each seven-day week to gather weekly activity levels. Days consisted of a randomly selected physical education day for each week, a randomly selected non-physical education day for each week and a Saturday and a Sunday for each week. School holidays during weekdays were not considered non-PE days.

Data reduction. PA data were reduced to the class level for activity levels. Since all classes completed six weeks of accelerometer wear-time, it was not necessary to use statistical techniques to replace missing data and allowed the use of full data without harmonic means. Although individual students' scores were being recorded, the unit of analysis for inferential statistics was the class (Silverman \& Solmon, 1998).

To analyse physical activity results, a $2 \times(\mathrm{Sex}) \times 4$ (Type of Day) $\times 6$ (Time) ANOVA with repeated measures was conducted using class means. Pairwise comparisons with a Bonferroni adjustment were used as post hoc tests. Significant results from ANOVAs are reported using the Greenhouse-Geisser adjustment. 


\section{Results}

Weekly Physical Activity by Class

Overall class means for physical activity ranged from a high of 13,700 steps ( $S D=6,219)$, which occurred on a Week 1 Non-PE Day to a low of 8,536 ( $\mathrm{SD}=3,814)$, which occurred on a Sunday in Week 5. Types of days (PE day, Non-PE Day, Sat, Sun) also showed wide ranges. Table 1 provides measures for PE days, Non-PE Days, Saturdays, and Sundays.

\begin{tabular}{|c|c|c|c|c|c|c|}
\hline Type of Day & Week 1 & Week 2 & Week 3 & Week 4 & Week 5 & Week 6 \\
\hline NOPE & $\begin{array}{c}14359.12 \\
4877.52 \\
21\end{array}$ & $\begin{array}{c}11629.26 \\
2459.35 \\
21\end{array}$ & $\begin{array}{c}11436.80 \\
2201.89 \\
21\end{array}$ & $\begin{array}{c}10331.26 \\
2700.42 \\
21\end{array}$ & $\begin{array}{c}10777.08 \\
2828.07 \\
21\end{array}$ & $\begin{array}{c}10355.84 \\
2764.46 \\
20\end{array}$ \\
\hline PE Day & $\begin{array}{c}12154.63 \\
2053.60 \\
21\end{array}$ & $\begin{array}{c}11734.66 \\
2242.97 \\
21\end{array}$ & $\begin{array}{c}11566.57 \\
1961.20 \\
20\end{array}$ & $\begin{array}{c}11566.09 \\
1614.08 \\
21\end{array}$ & $\begin{array}{c}12550.33 \\
3234.85 \\
21\end{array}$ & $\begin{array}{c}10675.67 \\
3503.70 \\
20\end{array}$ \\
\hline SAT & $\begin{array}{c}9495.06 \\
2474.49 \\
20\end{array}$ & $\begin{array}{c}10878.71 \\
4140.80 \\
21\end{array}$ & $\begin{array}{c}10543.88 \\
2771.25 \\
21\end{array}$ & $\begin{array}{c}10542.49 \\
3670.68 \\
21\end{array}$ & $\begin{array}{c}8864.80 \\
2138.35 \\
20\end{array}$ & $\begin{array}{c}10127.22 \\
4866.90 \\
20\end{array}$ \\
\hline SUN & $\begin{array}{c}9394.47 \\
2193.88 \\
20\end{array}$ & $\begin{array}{c}9989.07 \\
2815.82 \\
21\end{array}$ & $\begin{array}{c}9222.16 \\
2909.95 \\
19\end{array}$ & $\begin{array}{c}9909.33 \\
2993.73 \\
20\end{array}$ & $\begin{array}{c}8664.57 \\
2320.21 \\
20\end{array}$ & $\begin{array}{c}8984.35 \\
2770.90 \\
19\end{array}$ \\
\hline TOTAL & $\begin{array}{c}11397.31 \\
3713.17 \\
82\end{array}$ & $\begin{array}{c}11057.92 \\
3034.39 \\
84\end{array}$ & $\begin{array}{c}10717.86 \\
2608.80 \\
81\end{array}$ & $\begin{array}{c}10595.46 \\
2855.12 \\
83\end{array}$ & $\begin{array}{c}10249.55 \\
3071.19 \\
82\end{array}$ & $\begin{array}{c}10049.08 \\
3577.16 \\
79\end{array}$ \\
\hline
\end{tabular}

Note: PEDAY= day when student participated in organized physical education in school; NO PEDAY= regular school day without physical education; SAT= Saturday; SUN= Sunday. Scores are the mean, followed by standard deviation on the second line, and $N$ on the third line for each section.

\section{Physical Activity by Class and Sex}

The range of overall steps varied highly by type of day but not by sex. For example, boys recorded a high of $14,993$ ( $\mathrm{SD}=6,753)$ on a Non-PE Day (girls recorded 12,997 ( $\mathrm{SD}=5,654)$ on a Non-PE day), and girls recorded the overall low of 8,289 ( $S D=3,881$ ) for Sundays, yet boys were not far off by recording 8,544 steps $(S D=3,216)$ on a Sunday. This highlighted a pattern throughout the data of relatively consistent PA scores between sexes by type of day, yet wide ranges of scores in the type of day activity occurred (PE Day, Non-PE Day, Sat, Sun). Full data can be found in Table 2 .

\section{Total Physical Activity by Type of Day}

Average scores ranged from a high of $11,397(\mathrm{SD}=3,713)$ at Week 1 to a low of $10,049(\mathrm{SD}=3,577)$ at Week 6. Scores at Week 1 were notably higher than both Week 6 and Week 5 . Scores vary drastically within the 6-week period by type of day as was noted in the drop of total steps on a Non-PE day from $14,359(\mathrm{SD}=4,877)$ during Week 1 to the Week 6 total of $10,355(S D=2,764)$ showing a decline of over 4,000 steps in the means.

\section{Total Physical Activity by Sex and Type of Day}

The overall average number of weekly steps ranged from a high of $11,874(\mathrm{SD}=4,154)$ for male students in Week 1 to a low of $9,817(\mathrm{SD}=3,765)$ for female students in Week 6 . Week 1 data included the overall high in the group of 15,401 ( $\mathrm{SD}=5,351)$ for female students and male students 13,212 $(\mathrm{SD}=4,273)$, whereas Week 5 held the overall lows for male students $8,587(\mathrm{SD}=1,833)$ and female students $8,610(\mathrm{SD}=2,552)$ highlighting a trend of decreasing PA over time.

Physical activity by Type of Day and Sex. To determine if the participants' steps varied by the type of day, a $2($ Sex $) \times 4$ (Type of Day) $\times 6$ (Time) ANOVA with repeated measures on the last two factors was conducted by analysing PA scores as dependent variables (Week 1 to Week 6) and the type of day (PE, Non-PE, Sat, Sun), sex and time as the independent variables. There was a significant main effect of Time $[F(5,64)=3.18$, $\left.p<.05 \eta^{2}=.05\right]$ as well as a Time by Type of Day interaction $\left[F(15,177)=3.55, p<.001 \eta^{2}=.14\right]$. The Time by Sex interaction was not significant $\left[F(5,64)=.62, p>.05 \eta^{2}=.01\right]$ nor was the three-way Time by Sex by Type of Day interaction $\left[F(15,177)=.32, p>.05 \eta^{2}=.01\right]$. Tests of between-subject effects showed that there was a significant main effect of Type of Day $\left[F(3,68)=5.59, p<.01 \eta^{2}=.20\right]$. Sex was not significant $\left[F(1,68)=3.66, p=0.60 \eta^{2}=.05\right]$. Follow-up pairwise comparison tests with a Bonferroni adjustment showed that the main effect of Time was significant with Week $1(11,586 \mathrm{SD}=3,744)$ significantly $(p<.05)$ higher than Week $5(10,425 \mathrm{SD}=3,087)$ with a mean difference of $1,140.49$ steps more than Week 5 . Week 1 was also significantly $(p<.05)$ higher with a mean difference of $1,353.39$ steps more than Week $6(10,168(S D=3,573))$. Follow-up pairwise comparison tests with a Bonferroni adjustment for Type of Day showed students were on average (mean difference $=2,150.67$ steps $\mathrm{SE}=683.95)$ significantly $(p<.05)$ more active on Non-PE Days than Sundays, and students were significantly $(p<.01)$ more active (mean difference $=2,453.95$ steps $S E=683.95$ ) on PE Days than Sundays. The Time by Type of Day interaction showed PA peaking during the Week 1 measures (Non-PE Day mean=14,651 $(\mathrm{SD}=4,811)$ ) yet dropping significantly to $10,355(\mathrm{SD}=2,764)$ by Week 6 . 
TABLE 2 Total Physical Activity by Sex

\begin{tabular}{|c|c|c|c|c|c|c|c|}
\hline Type of Day & Sex & Week 1 & Week 2 & Week 3 & Week 4 & Week 5 & Week 6 \\
\hline \multirow[t]{6}{*}{ PEDAY } & Male & 12341.37 & 12242.40 & 12190.17 & 12083.87 & 12628.49 & 11317.71 \\
\hline & & 2500.64 & 2069.73 & 1853.75 & 1200.53 & 3323.45 & 2797.65 \\
\hline & & 11 & 11 & 10 & 11 & 11 & 10 \\
\hline & Female & 11949.22 & 11176.15 & 10942.97 & 10996.55 & 12464.34 & 10033.64 \\
\hline & & 1527.82 & 2399.67 & 1954.34 & 1870.82 & 3311.44 & 4144.04 \\
\hline & & 10 & 10 & 10 & 10 & 10 & 10 \\
\hline \multirow[t]{6}{*}{ NO PEDAY } & Male & 15401.40 & 12246.54 & 12258.44 & 10966.06 & 11591.79 & 10746.86 \\
\hline & & 5351.25 & 2183.05 & 2261.98 & 2832.56 & 2523.98 & 2189.49 \\
\hline & & 11 & 11 & 11 & 11 & 11 & 10 \\
\hline & Female & 13212.62 & 10950.26 & 10533.00 & 9632.99 & 9880.91 & 9964.81 \\
\hline & & 4273.31 & 2677.26 & 1832.02 & 2501.17 & 2998.58 & 3316.63 \\
\hline & & 10 & 10 & 10 & 10 & 10 & 10 \\
\hline \multirow[t]{6}{*}{ SAT } & Male & 10025.75 & 11552.10 & 10047.06 & 11083.16 & 9118.78 & 9985.03 \\
\hline & & 2922.88 & 4677.55 & 2430.50 & 3485.26 & 1730.82 & 5467.53 \\
\hline & & 10 & 11 & 11 & 11 & 10 & 10 \\
\hline & Female & 8964.36 & 10137.98 & 11090.37 & 9947.75 & 8610.81 & 10269.41 \\
\hline & & 1938.42 & 3553.62 & 3141.51 & 3961.69 & 2552.26 & 4479.57 \\
\hline & & 10 & 10 & 10 & 10 & 10 & 10 \\
\hline \multirow[t]{6}{*}{ SUN } & Male & 9331.81 & 10757.29 & 9120.62 & 10185.98 & 8587.40 & 8965.23 \\
\hline & & 2210.05 & 2197.58 & 1734.63 & 3245.42 & 1833.08 & 1896.94 \\
\hline & & 10 & 11 & 10 & 11 & 11 & 9 \\
\hline & Female & 9457.13 & 9144.02 & 9334.98 & 9571.20 & 8758.89 & 9001.56 \\
\hline & & 2295.20 & 3277.04 & 3954.79 & 2808.18 & 2926.96 & 3486.62 \\
\hline & & 10 & 10 & 9 & 9 & 9 & 10 \\
\hline \multirow[t]{3}{*}{ Total } & Male & 11874.91 & 11699.58 & 10915.92 & 11079.77 & 10513.31 & 10286.74 \\
\hline & & 4154.92 & 2949.66 & 2443.73 & 2817.98 & 2915.38 & 3405.84 \\
\hline & & 42 & 44 & 42 & 44 & 43 & 39 \\
\hline \multirow[t]{3}{*}{ Total } & Female & 10895.83 & 10352.10 & 10504.57 & 10049.07 & 9958.73 & 9817.35 \\
\hline & & 3159.69 & 3004.53 & 2791.90 & 2833.13 & 3247.44 & 3765.39 \\
\hline & & 40 & 40 & 39 & 39 & 39 & 40 \\
\hline
\end{tabular}

\section{Discussion}

The purpose of this study was to track student PA levels over the course of six weeks in a free-living environment. We wanted to ascertain if students' activity levels varied based on whether or not they had physical education class and how PA levels fluctuated during weekends. Some of the results confirm prior research, such as physical activity levels declining by age (Pate et al., 2009). Prior research with adolescents shows that in order to attain the recommended 60-minutes of moderate to vigorous physical activity (MVPA) boys and girls need to get to 10,000-11,700 steps per day (Tudor-Locke et al., 2011). The results of this study show that although weekly average steps are within this range during the 6-week period of the study, there were several time points where this range was not reached, specifically during weekends.

Research suggests that youth do not engage in adequate amounts of physical activity (IOM, 2013). Overall, students in this study, were active in ranges (10,000-11,700 steps) which research suggests, when reached, may show that adolescents are indeed attaining 60-minutes of moderate to vigorous physical activity a day (Tudor-Locke et al., 2011). These data are reported weekly averages and are the combination of a PE day, Non PE day, and two weekend days. For Saturday and Sunday alone the 10,000-step threshold was not often met. Students were significantly more active on PE days and Non-PE days than Sundays. It seems that in school even when PE is not held, students receive significantly more activity than when they are at home on weekends. This result is in line with a recent meta-analysis of 37 accelerometer studies looking at youth PA that also suggested students are more active during weekdays than weekends (Brooke, Corder, Atkin, \& van Sluijs, 2014). Data from this study brings to light important information on weekend habits of students and increases the importance of physical educators promoting lifetime wellness that carries over to out-of-school time, as a recent review noted that "school physical education probably has the greatest reach" (Sallis, Carlson, \& Mignano, 2012: 504) on PA levels of students.

Sundays were the least active days in the study. This is not unusual as past research shows that Sundays had the highest levels of inactivity (Scheers, Philippaerts, \& Lefevre, 2012). The lack of activity on Sundays may be due to a lack of organized activities available for adolescents (Comte et al., 2013). We do not yet know if this is due to a lack of interest in organized activities on Sundays and how these activities may clash with the culture of the child's community. The lack of activity on Sundays further strengthens the argument to compensate for the loss of active time with more PA during the week in PE classes and after school PA programs. There 
were no significant differences between Saturdays and PE days or Non-PE days. Although on the average PE Day and Non-PE day students were getting enough PA to get 60 -min of MVPA, 75\% of the weekend days measured, did not reach this threshold. Past research shows increases in sitting, TV/electronics, and chores on weekend days (Jago, Anderson, Baranowski, \& Watson, 2005), which may explain the reduced weekend activity in this study. These data may add to the research on the importance of physical activity not only in physical education class but the PA students receive in and around the school day.

Reaching fitness guidelines. In the U.S.A., national recommendations suggest the girls (ages 6-17) should aim for 11,000 and boys should aim for 13,000 steps per day (The President's Council on Fitness, Sports \& Nutrition, 2015). The students in this study on average did not meet these goals regularly. Boys on average never reached the 13,000-step recommendation on PE days, Saturdays, or Sundays. Conversely, girls reached or were within 60 steps of their suggested $(11,000)$ ranges five out of six weeks when they participated in PE. Girls only met the recommendations once during non-PE-Days (during Week 1). These data highlight the importance of physical education for young adolescent girls. Girls are not meeting national recommendations regularly unless they are getting physical education in school.

The National Association for Sport and Physical Education (NASPE) recommends middle school students get 225 minutes of PE each week (NASPE, 2012). Students in this study may not have been reaching the national recommendations for physical activity (11,000 steps for girls 13,000 steps for boys) regularly as none of the schools in this study attained the NASPE recommendations for minutes of PE. Most of the schools had PE twice or three times a week, with a range of PE minutes from 90 to 150 minutes per week. The reality of PE in the USA is that daily PE has declined from 1999-2011 (Eaton et al., 2012). Research suggests that increasing PE time in schools and physical activity in schools does not negatively affect academic scores (IOM, 2013), yet the trend of cutting PE hours continues. Girls in this study only reached the national recommendations regularly on PE-days. Therefore, the less common daily PE becomes and the inability of schools to reach PE time recommendations increases, the less likely it is that students, specifically adolescent girls, will be sufficiently active to gain health benefits. There is a need to develop more opportunities for young girls to be active outside of school or in well-developed after school activity programmes so girls can attain the same level of PA as they do on PE days. Past research shows a marked sex difference, with girls showing higher inactivity, in late afternoon physical activity and recommends this time for possible interventions (Jago et al., 2005).

Spike at the beginning of study. There is an interesting physical activity spike at the beginning of the study. Across all categories of days, the Week 1 data point contains the highest number of steps in comparison to all other data points. It begins higher and then drops to a consistent level in subsequent weeks, especially on Saturdays and non-PE days. This may be due to the novelty of the new technology piquing the students' interest followed by the eventual, yet relatively quick, return to normal levels. Prior research examines the motivational effect of activity monitors showed a significant decline in PA from the beginning to the end of data collection (Ho et al., 2013), mirroring data in this research. Ho et al. (2013) showed that girls who wore an activity monitor had more steps than those who did not. It is difficult to generalize findings from the current study as it spanned a considerably longer period of data monitoring than past studies using accelerometers.

The accelerometers may indeed have excited the students to take more steps. If this occurred, it happened immediately when students received the units during Week 1 , and then the steps returned to their normal levels. Following the spike in PA during Week 1, the PA levels began a decline yet were still above national averages (Tudor-Locke, Johnson \& Katzmarzyk, 2010). When students first received their MOVBands, many were observed instantly running around and jumping rope or even doing cartwheels to see how those movements measured up to steps in their accelerometer. The study of Ho et al. (2013) noted the possibility of higher PA associated with the use of an activity monitor but noted that it was short-lived and mainly associated with girls, which could further explain the spike at the first data collection time. A review on whether pedometers increased PA in intervention studies showed a moderate and positive increase in PA levels (Kang, Marshall, Barreira \& Lee, 2009), which may partially explain the peak of PA at Week 1 in this study.

The highest scores were found during non-PE Days in Week 1 (often the first full-day the students had the device) for boys and girls. Future research should examine how to capture and build on the initial excitement present in this and other studies to determine how accelerometers can be used as a motivating tool to increase PA. Although students participating in this unit were taking more steps than the average U.S. student takes, (Tudor-Locke, Johnson \& Katzmarzyk, 2010) the effect of the accelerometer as a motivating factor, if at all, was short lived. Students did not experience lasting high levels of PA over six weeks, yet it is difficult to ignore the spike in PA levels with the introduction of the accelerometers to students. Future research should examine ways that curricula may affect PA levels when using new and emerging technologies, such as accelerometers. Past research has shown an increase in physical activity when participating in curricula that are technology driven, such as HOPSports (West \& Shores, 2014). Perhaps a long-term intervention, similar to past curricular interventions such as SPARK (Sallis et al., 1997) or CATCH (Luepker et al., 1996), can have a more profound effect on PA levels.

All-female physical education. Class level data showed that Class 4 was significantly lower than four other classes based on steps taken and ranged from 3,908 to 5,050 steps lower than the others. Class 4 was also the only all-female PE class in the study. Although, legally students should not be in single sex PE classes in the 
U.S.A. (United States Department of Education, 2002) there were two classes that were split between sexes at one of the schools. The single sex classes were not significantly different from each other in number of steps taken, yet the all- female class had one of the lowest PA levels in the study. The all-female class scored below the co-ed class average physical activity at every measurement point throughout the study. This is in line with past research (McKenzie, Prochaska, Sallis, \& LaMaster, 2004) that showed students in all-female PE classes record significantly less MVPA than their co-educational class peers.

The results of this study bring to light many different topics that further extend our knowledge of young students' physical activity habits. The U.S.A battles similar health issues as many other countries around the world do. Although this research followed a population of students in Northeast U.S.A., similarities run parallel to other countries and the issues they face with getting students physically active. As shown in past research, (Dudley et al., 2011) physical education is crucial in increasing young students' physical activity levels. PE is important especially for young girls who only reached the goal set by the Presidential Council for Fitness, Nutrition and Sport on days when they participated in physical education, and only once on Non-PE days or weekends over six weeks of monitoring. This suggests that more attention needs to be paid to specific subgroups such as young girls to increase their attitudes toward PE (Prochaska et al., 2003). Not only are high amounts of physical activity related to healthy living (CDC, 1997), but enjoyable experiences encourage participation in physical education and physical activity (CDC, 1997; Dismore \& Bailey, 2011). Additionally, after school programs could help fill the lack of available PA during school by providing young girls opportunities to be physically active in after school programs if indeed the trend of not providing daily $\mathrm{PE}$ in schools continues. Future research on physical activity interventions for young girls in out-of-school environments should be pursued.

\section{REF ER E N C E S}

Brooke, H.L., Corder, K., Atkin, A.J., \& van Sluijs, E.M.F. (2014). A systematic literature review with metaanalyses of within- and between-day differences in objectively measured physical activity in school-aged children. Sports Medicine (Auckland, N.Z.), 44(10), 1427-1438.

Centers for Disease Control and Prevention (CDC). (1997). Guidelines for school and community programs to promote lifelong physical activity among young people. Morbidity and Mortality Weekly Report, 46(No. RR-6). Retrieved from: http://www.cdc.gov/mmwr/pdf/rr/rr4606.pdf

Chen, S., Kim, Y., \& Gao, Z. (2014). The contributing role of physical education in youth's daily physical activity and sedentary behavior. BMC Public Health, 14, 110.

Chinapaw, M.J.M., de Niet, M., Verloigne, M., Bourdeaudhuij, I. De, Brug, J., \& Altenburg, T. M. (2014). From sedentary time to sedentary patterns: Accelerometer data reduction decisions in youth. PLoS ONE, 9(11), e111205. doi:10.1371/journal.pone.0111205

Comte, M., Hobin, E., Majumdar, S.R., Plotnikoff, R.C., Ball, G.D.C., \& McGavock, J. (2013). Patterns of weekday and weekend physical activity in youth in 2 Canadian provinces. Applied Physiology, Nutrition, and Metabolism, 38(2), 115-119.

Crouter, S.E., Schneider, P.L., Karabulut, M., \& Bassett, D.R. (2003). Validity of 10 electronic pedometers for measuring steps, distance, and energy cost. Medicine and Science in Sports and Exercise, 35(5), 1455-1460.

Dismore, H., \& Bailey, R. (2011). Fun and enjoyment in physical education: Young people's attitudes. Research Papers in Education, 26(4), 499-516.

Dudley, D., Okely, A., Pearson, P., \& Cotton, W. (2011). A systematic review of the effectiveness of physical education and school sport interventions targeting physical activity, movement skills and enjoyment of physical activity. European Physical Education Review, 17(3), 353-378.

Eaton, D.K., Kann, L., Kinchen, S., Shanklin, S., Flint, K.H., Hawkins, J., ... Wechsler, H. (2012). Youth risk behavior surveillance - United States, 2011. Morbidity and Mortality Weekly Report. Surveillance Summaries, 61(4), 1-162.

Gibbone, A., Rukavina, P., \& Silverman, S. (2010). Technology integration in secondary physical education: Teachers' attitudes and practice. Journal of Educational Technology Development and Exchange, 3(1), 2742.

Ho, V., Simmons, R.K., Ridgway, C.L., van Sluijs, E.M.F., Bamber, D.J., Goodyer, I.M., ... Corder, K. (2013). Is wearing a pedometer associated with higher physical activity among adolescents? Preventive Medicine, 56(5), 273-277.

IOM (Institute of Medicine). (2013). Educating the student body: Taking physical activity and physical education to school. Washington, DC: The National Academies Press.

Jago, R., Anderson, C.B., Baranowski, T., \& Watson, K. (2005). Adolescent patterns of physical activity: Differences by gender, day, and time of day. American Journal of Preventive Medicine, 28(5), 447-452.

Kang, M., Marshall, S.J., Barreira, T.V., \& Lee, J.O. (2009). Effect of pedometer-based physical activity interventions: A meta-analysis. Research Quarterly for Exercise and Sport, 80(3), 648-655.

Luepker, R. V, Perry, C. L., Mckinlay, S. M., Nader, P. R., Parcel, G. S., Stone, E. J., .. Wu., M. (1996). Outcomes of a field trial to improve children's dietary patterns and physical activity. JAMA, 275(10).

Marttinen, R., \& Fredrick, R. (in press 2016). Fitness Integrated with Technology (F.I.T.) Curriculum: Connecting Technology and Physical Education. In Fédération Internationale d' Éducation Physique: Connecting Technology and Physical Education. 
McKenzie, T. L., Sallis, J. F., \& Nader, P. R. (1991). SOFIT: System for observing fitness instruction time. Journal of Teacher Education, 11(2), 195-205.

McKenzie, T.L., Prochaska, J.J., Sallis, J.F., \& LaMaster, K.J. (2004). Coeducational and single-sex physical education in middle schools: Impact on physical activity. Research Quarterly for Exercise and Sport, 75(4), 446-449.

Menickelli, J., Sidman, C., Claxton, D., Grube, D., Leonard, E., \& Lowell, S. (2013, March). Convergent Validity of an Activity Monitor With a Research-Grade Accelerometer. Poster Presented at the Research Consortium for the 2013 AAHPERD National Convention and Exposition, Charlotte, NC.

National Association for Sport and Physical Education (2009). Appropriate Instructional Practice Guidelines for Elementary Physical Education Reston, VA: Author.

National Association for Sport and Physical Education (NASPE). (2012). 2012 Shape of the nation report: Status of physical education in the USA. Reston, VA: American Alliance for Health, Physical Education, Recreation and Dance.

Pate, R. R., Ross, R., Dowda, M., Trost, S. G., \& Sirard, J. R. (2003). Validation of a 3-Day physical activity recall instrument in female youth. Pediatric Exercise Science, 15, 257-265.

Pate, R.R., Stevens, J., Webber, L.S., Dowda, M., Murray, D.M., Young, D.R., \& Going, S. (2009). Age-related change in physical activity in adolescent girls. The Journal of Adolescent Health, 44(4), 275-282.

U.S. Department of Health and Human Services (2008). Physical activity guidelines advisory committee report. Washington: DC: U.S. Department of Health and Human Services.

President's Council for Fitness, Sports and Nutrition (2015). President's Challenge. Retrieved from: https:// www.presidentschallenge.org/tools-resources/docs/PALA+_log_zine.pdf

Prochaska, J.J., Sallis, J., Slymen, D.J., \& McKenzie, T.L. (2003). A longitudinal study of children's enjoyment of physical education. Pediatric Exercise Science, 15(2), 170-178.

Rich, C., Geraci, M., Griffiths, L., Sera, F., Dezateux, C., \& Cortina-Borja, M. (2013). Quality control methods in accelerometer data processing: Defining minimum wear time. PLoS ONE, 8(6), e67206 doi:10.1371/ journal.pone.0067206

Sallis, J.F., Carlson, J.A., \& Mignano, A.M. (2012). Promoting youth physical activity through physical education and after-school programs. Adolescent Medicine State of the Art Reviews, 23(3), 493-510.

Sallis, J.F., McKenzie, T.L., Alcaraz, J.E., Kolody, B., Faucette, N., \& Hovell, M.F. (1997). The effects of a 2 -year physical education program ( SPARK) on physical activity and fitness in elementary school students. American Journal of Public Health, 87(8), 1328-1334.

Sallis, J.F., McKenzie, T.L., Kolody, B., Lewis, M., \& Marshall, S. (1999). Effects of health-related physical education on academic achievement: Project SPARK. Research Quarterly for Exercise and Sport, 70(2), 127-134.

Scheers, T., Philippaerts, R., \& Lefevre, J. (2012). Variability in physical activity patterns as measured by the SenseWear Armband: How many days are needed? European Journal of Applied Physiology, 112(5), 16531662.

Silverman, S., \& Solmon, M. (1998). The unit of analysis in field research: Issues and approaches to design and data analysis. Journal of Teaching in Physical Education, 17, 270-284.

Stewart, J. A, Dennison, D. A, Kohl, H. W., \& Doyle, J. A. (2004). Exercise level and energy expenditure in the TAKE 10! in-class physical activity program. The Journal of School Health, 74(10), 397-400.

Trost, S.G., Mciver, K.L., \& Pate, R.R. (2005). Conducting accelerometer-based activity assessments in fieldbased research. Medicine \& Science in Sports \& Exercise, 37(Supplement), S531-S543.

Tudor-Locke, C., Craig, C.L., Beets, M.W., Belton, S., Cardon, G.M., Duncan, S., ... Blair, S. N. (2011). How many steps/day are enough? for children and adolescents. The International Journal of Behavioral Nutrition and Physical Activity, 8(1), 78 doi:10.1186/1479-5868-8-78

Tudor-Locke, C., Johnson, W.D., \& Katzmarzyk, P.T. (2010). Accelerometer-determined steps per day in US children and youth. Medicine and Science in Sports and Exercise, 42(16), 2244-2250.

Tudor-Locke, C., McClain, J.J., Hart, T.L., Sisson, B.S., \& Washington, T.L. (2009). Pedometry methods for assessing free-living adults. Research Quarterly for Exercise and Sport, 80(2), 175-184.

U.S. Department of Education. Promoting educational excellence for all Americans (2002). Retrieved from: https://www2.ed.gov/policy/rights/guid/ocr/edlite-t9-guidelines-ss.html.

West, S. W., \& Shores, K. A. (2014). Does HOPSports promote youth physical activity in physical education classes? Physical Educator, 71(1), 16-40. 